\title{
Editorial
}

\section{A futuristic educational perspective for health practioners.}

Dr Leila Ali

Continuing Medical Education (CME) is a concept developed and used since the 1970's in. Its efficiency in ensuring medical practioners up-to-date is no more discussable nowadays. The terms Continuing Professional Development (CPD) and Continuing Medical Education (CME) are usually used interchangeably. However, the CME should be considered as a component of CPD. The CPD system establishes a balance between group learning, self-directed learning, and assessment activities.

The educational goals of CPD includes expanding knowledge, acquiring skills, developing new competencies, improving performance and patient care outcomes, as well as supporting multiple transitions as a natural part of career development.

Adults learning is a more complex process. This may be due to many unpredited factors; such as the lack of information, reduced motivation, time unavailability, and the wrong perception of scientific education necessity. Different objective studies have proven that continuous learning process is multi-dimensional and could be held in different approaches for adults. Continuous education for health practioners is a more sophisticated process. The clinical practice requires a specific orientation for self- learning; system thinking management; and team working ability.

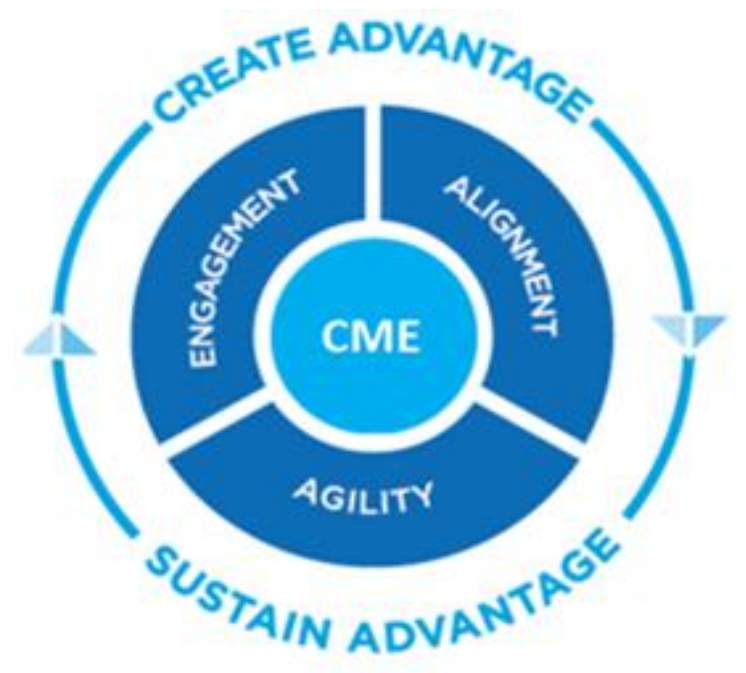

CME initiative reinforces active information seeking, and sets the best learning atmosphere for health practioners. who are struggling to be up-to-date either due to lack of necessary information or sometimes due to its excess. 
It makes an environment of collective decision-making and contribute to the elaboration of standards and guidelines. CPD includes a focus on discipline-specific knowledge and embraces learning across a wide range of content. It is a lifelong learning process which enables health professionals to maintain and improve different skills such as communication; leadership and management; evidence based practice and clinical guidelines; and quality improvement.

The educational goals will not only provide measureable outcomes for healthcare practitioners but also establish the value and commitment of each one.

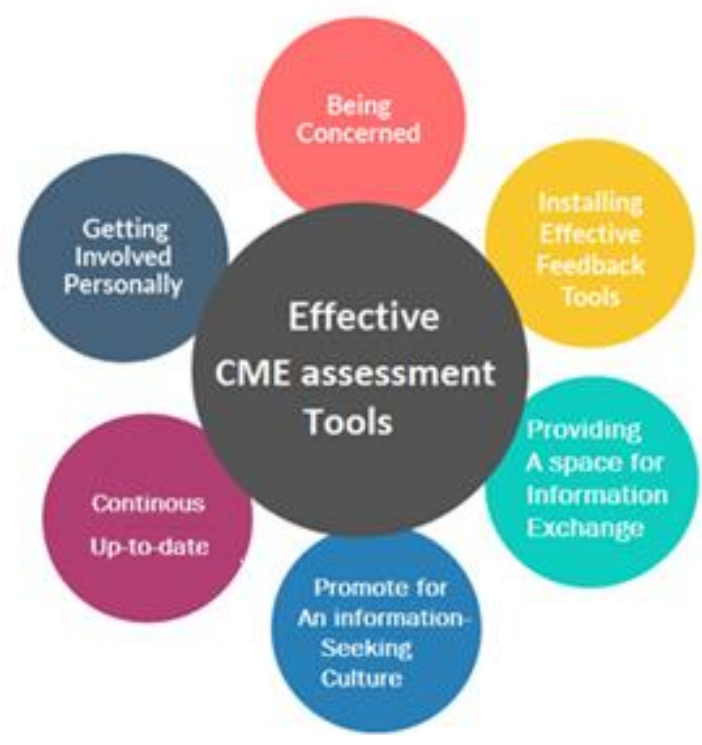

In order to ensure health practioners engagement in CPD, a credit points system is established. For each self-learning, group learning, and assessment activities; the points are assigned according to the aims fulfilled and the number of hours spent to complete the target. The renewal of the parctionner license belong to a sufficient number of credit points in any countries.

Unfortunately, in Tunisia this concept is not yet developed. This could revolutionize the health practice once established. 